\title{
In memoriam Hannes Kappeler (1933-2019)
}

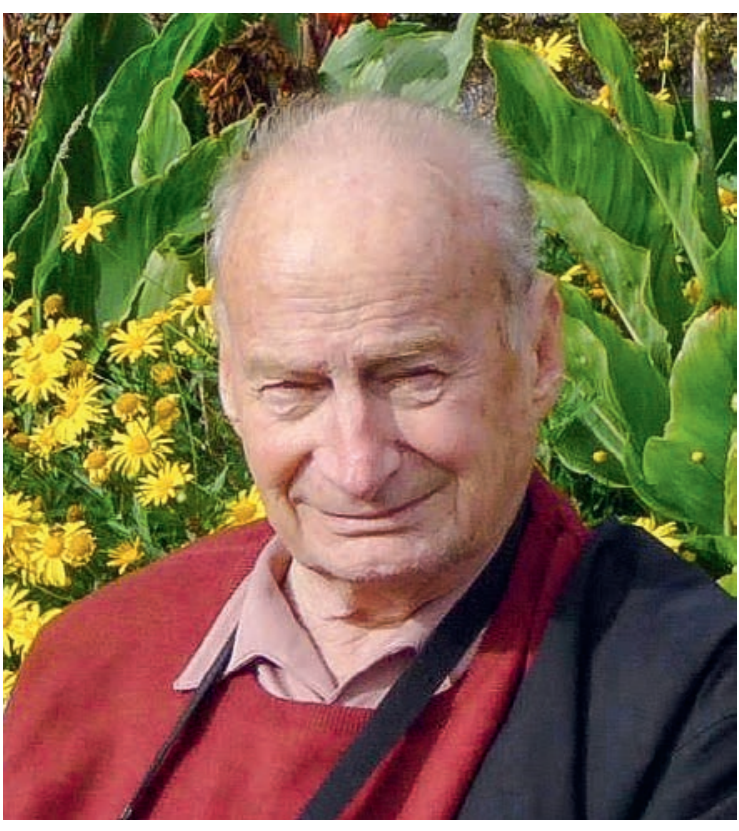

Hannes Kappeler

Hannes Kappeler ist am 3. Februar 2019 umgeben von seiner Familie friedlich eingeschlafen. Während vielen Jahren hatte er die Endokrinologie-Diabetologie in der Schweiz positiv beeinflusst.

Eine umfassende humanistische Ausbildung im Kloster-Gymnasium Einsiedeln hat ihn zeitlebens begleitet. Das Medizinstudium absolvierte er in Fribourg, Genf, Paris, Wien und Zürich, die Ausbildung in innerer Medizin und Endokrinologie-Diabetologie in Zürich, Solothurn und Genf. Im Jahre 1973 eröffnete er in Winterthur eine Praxis für Endokrinologie (und Diabetologie). Es war die erste dieser Spezialität im Kanton Zürich und entsprach seiner Auffassung, dass die Mehrzahl der endokrinen Erkrankungen ambulant in der freien Praxis abgeklärt und behandelt werden können. Als langjähriger Konsiliararzt am Kantonsspital Winterthur schuf er eine Brücke zwischen Spital und Praxis. In der Schweizerischen Diabetesgesellschaft - als Präsident der Ärztekommission - war er seinerzeit verantwortlich für die schweizweite Umstellung von Insulin U-40 zu U-100, was eine ausserordentliche organisatorische Leistung erforderte. Eine dezidierte Meinung vertrat er damals in der Frage, ob das eingeführte Humaninsulin für Patienten gefährlich sein könnte. Er war nicht nur ein begabter Redner, sondern auch ein begabter Schreiber. Als Redak- tionsmitglied des D-Journals schrieb er für Diabetiker viele nützliche und interessante Artikel.

Unvergesslich sind die Winterthurer Fortbildungstage, die er während vielen Jahren mit organisatorischer Perfektion durchführte. Dass er mit praxisnahen Themen immer wieder das Theater Winterthur füllen konnte, war aussergewöhnlich.

Seine vielseitigen Begabungen erlaubten ihm auch nach der Praxisübergabe im Jahre 2003 an seinen Sohn Dirk, seine Hobbys aktiv zu pflegen.

Mit der Aufgabe der Praxis verlor Hannes das Interesse an der Medizin, insbesondere an der, die ihn in späteren Jahren selber als Patienten betraf. Er liess die anderen Mediziner walten und akzeptierte deren Meinungen. Wenn man dann kritisch nachfragte, meinte er «ich bin nicht mehr Doktor».

Musik, Kunstgeschichte, Geschichte, schon früher zentral in seinem Interessenbereich, rückten nun in den Vordergrund. Er schrieb sich an der Universität Zürich in diesen Fächern ein und zwar als ordentlicher Student, beteiligte sich an Seminaren und benutzte dabei auch einen Laptop - der früher in der Arztpraxis noch terra incognita war. Es war sein Ehrgeiz, mit den Studenten mithalten zu können oder diese sogar zu übertreffen. Uns Kollegen und Interessierte führte er zu den mittelalterlichen Wandmalereien in Winterthur und weiterer Umgebung, auf die Insel Ufenau, ins Kloster Einsiedeln, an den Bodensee. Er besuchte Konzerte und Opern, wobei sein Herz besonders für die alte Musik schlug. Und er verfasste im Eigenverlag kleine Broschüren, dies schon während seiner Praxistätigkeit:

«100 Heilige und ihre Attribute», «Die Reformation im Thurgau», "Die Insel Ufnau», "Die Liebschaften des Zeus», «Habsburger Gedenkstätten in der Schweiz und im Schwarzwald» und andere.

Vielen Ärzten wird Hannes Kappeler mit seinem Ideenreichtum und seiner Begabung als Schaffer und Macher in Erinnerung bleiben.

Wir sind dankbar für die vielen Stunden und Tage, die wir mit ihm und seiner Gemahlin Renate verbringen durften.

«Lebe wohl, Hannes!» Dr. med. Klaus Ganz 